\title{
The Synergistic Effects of Agarose Scaffold Supplemented with Low-molecular-weight Silk Fibroin in Bone Tissue Regeneration
}

\author{
Seung-Won Park*, Tae-Won Goo, Seong Ryul Kim, HaeYong Kweon, Seok-Woo Kang* \\ Department of Agricultural Biology, National Academy of Agricultural Science, Rural Development Association, Suwon 441- \\ 1010, Republic of Korea
}

(Received 06 September 2011; Accepted 10 November 2011)

\begin{abstract}
Silk protein and agarose are widely known as biocompatible materials in the human body. A three-dimensional (3D) scaffold composed of agarose and lowmolecular-weight silk fibroin (LSF) was fabricated and examined in terms of structural characteristics and cellular responses in bone tissue engineering. This study showed that mouse pluripotent precursor cells attached to and proliferated uniformly on and within the LSF-containing 3D scaffold. Interestingly, cell proliferation and attachment was shown to be higher in a 3D scaffold containing $0.02 \%$ LSF, as compared to other LSF concentrations. The results of this study suggest that agarose-LSF scaffolds may be useful materials for tissue engineering.
\end{abstract}

Keywords: LSF, Agarose hydrogel, $3 D$ scaffold, Biomaterial, Bone tissue engineering

\section{Introduction}

Agar is mainly composed of $70 \%$ agarose and $30 \%$ agaropectin. It is a gelatinous substance derived from natural products (marine red algae; Gelidium and sea string) (Aymard et al., 2001; Park et al., 2010), and used as food additives. Its extensive use for human consumption makes agarose a biomaterial that has a good biocompatibility with the human body. In the biomedical research fields, biocompatible agarose gel has been used in cell culture, recombinant virus titration, nucleic acid analysis, cell encapsulation,

\footnotetext{
*To whom the correspondence addressed

Sericultural \& Apicultural Materials Division, National Academy of Agricultural Science, RDA, Suwon 441-100, Republic of Korea.

Tel: +82-31-290-8493; Fax +82-31-390-8503;

E-mail: microsw@korea.kr, kangsw@korea.kr
}

and in vivo transplantation applications (Park et al., 2010; Rahfoth et al., 1998; Uludag et al., 2000). Agarose gel can serve as an internal porous microenvironment that can mimic native tissues (Park et al., 2010). For several decades, studies on tissue regeneration have focused on developing three-dimensional (3D) porous scaffolds for the culture and growth of cells. An ideal scaffold should show features of biocompatibility to cells, biodegradability into smaller molecules, and microstructural stability.

One approach in human tissue engineering is in vitro cell culture using 3D scaffolds (Koch et al., 2010). Synthetic biodegradable polymers have been reported to induce acute inflammation reactions in tissues (Taylor et al., 1994), whereas silk protein generates less inflammation and thrombogenic reactions (Meinel et al., 2005; Santin et al., 1999). Silk has been used in operating sutures for thousands of years and currently, the U.S. Food and Drug Administration (FDA) has approved its distribution and use as a biomaterial (Cao et al., 2009; Kim et al., 2010). In vitro studies have identified sericin as one of the causative factors of an inflammatory response, yet other studies examining the macrophage response to fibroin concluded that silk does not elicit any significant macrophage activation (Kearns et al., 2008). On the basis of the latter results, silk fibroin solutions were used in 3D scaffold studies for bone tissue engineering (Kearns et al., 2008).

Interestingly, Kim et al. (2010) published that lowmolecular-weight silk fibroin protein (LSF) has a positive effect on osteoblast differentiation. Osteogenic gene expressions increased after the introduction of silk fibroin to MG-63 cells. Furthermore, Park et al. (2010) developed a porous cell-laden agarose fluidic device that characterized the physical and mechanical properties of agarose gels with various micropores. On the basis of these earlier reports, this study aims to develop a 3D culture system for bone tissue engineering that combines agarose and LSF derived from natural products. An agarose-based 3D scaf- 
fold provides the features of an optimal physiological environment such as high water content, high porosity, and mechanical support (Park et al., 2010). For clinical therapies, osteogenic growth factors are administered either systemically or via direct injection into the tissue site of interest. However, the short half-life, high dosage, cost, and potential toxicity at the systemic level have hindered the clinical application of these bioactive compounds (Edelman et al., 1993; Wang et al., 2009). To overcome these problems, this study describes the development of 3D scaffolds by using agarose and LSF. LSF is employed as an osteogenic pathway activator of $\mathrm{C} 2 \mathrm{C} 12$ cells (mouse pluripotent precursor cell line). 3D scaffolds composed of agarose and LSF could serve as a potentially useful tool in bone tissue engineering.

\section{Materials and Methods}

\section{Materials}

LSF was a gift from Dr. Kweon of the Rural Development Administration. The preparation of LSF is described in a previous study (Kim et al., 2010). BHK and C2C12 cells were a gift from the Waterborne Virus Bank, The Catholic University School of Medicine and Dr. Lee of The Ewha Women's University. The cells were grown in Dulbecco's modified Eagle's medium (DMEM) supplemented with $10 \%$ fetal bovine serum. Low-melting temperature agarose (SeaPlaque ${ }^{\circledR}$ ) was supplied by Lonza Corporation (Rockland, ME). This agarose melts in distilled water under $65^{\circ} \mathrm{C}$ and has a gelling temperature range of $26^{\circ} \mathrm{C}$ to $30^{\circ} \mathrm{C}$.

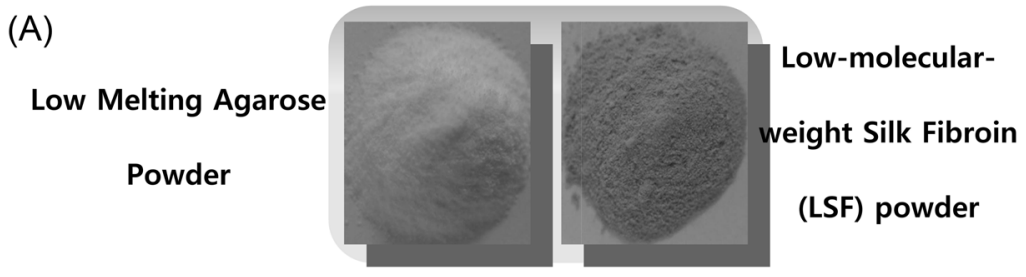

(B)

$$
1 \% \text { Agarose + Low-molecular-weight Silk Fibroin (LSF) }
$$

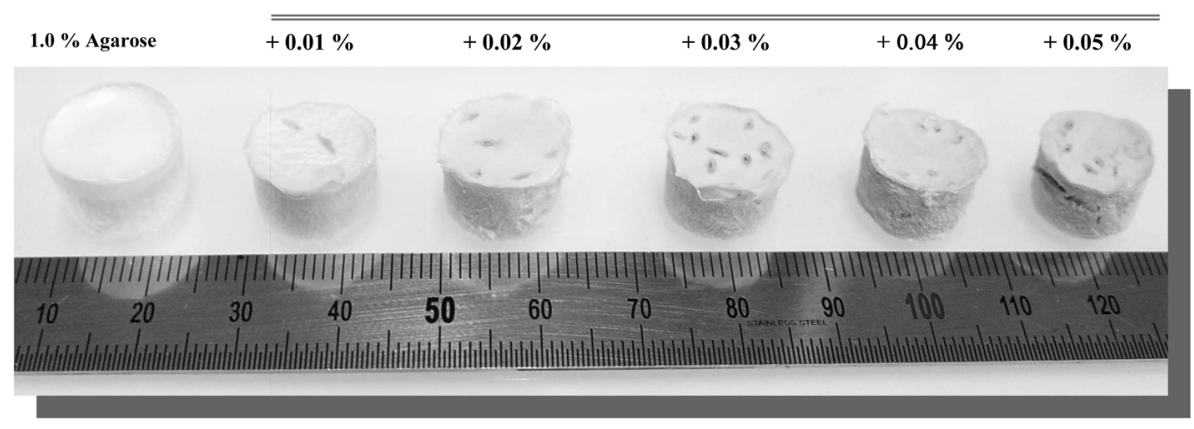

(C)
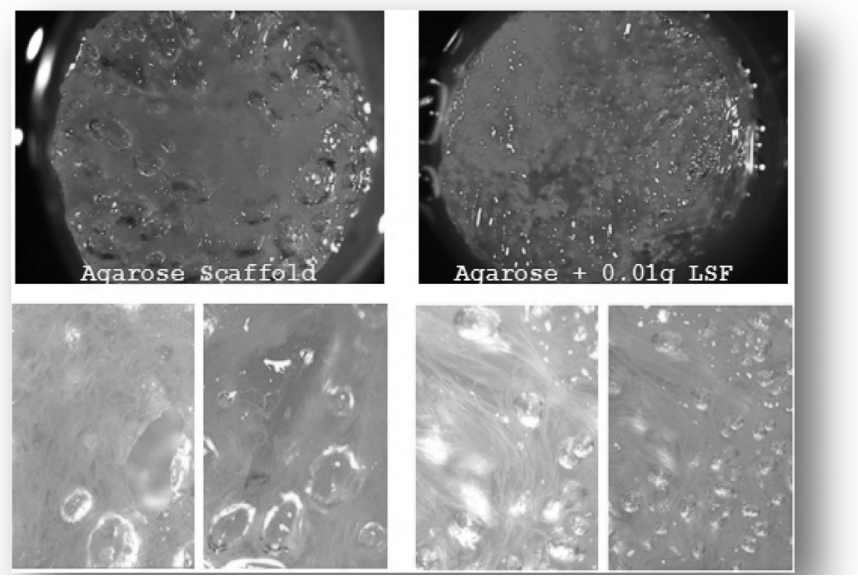

Fig. 1. (A) The agarose-LSF scaffolds mixed with low melting temperature agarose (left) and LSF (right). (B) The aqueous-derived agarose solution was mixed with different concentrations of LSF at various ratios $(0-0.05 \%)$. (C) Macroscopic analysis of the porous structure of 3D scaffolds without (left) and with LSF (right). 


\section{D scaffolds}

Microporous agarose scaffolds containing LSF were developed, as shown in Fig. 1. To prepare a 100-mL stock of 3\% (w/v) SeaPlaque $\AA$ agarose, $0.3 \mathrm{~g}$ agarose was dissolved in $100 \mathrm{~mL}$ sterile distilled water and warmed up in a microwave. The solution was then kept in a $50^{\circ} \mathrm{C}$ water bath until use. The 3\% agarose stock solution was then diluted with distilled water to $1 \%$. LSF at varying concentrations from 0 to $0.05 \%(\mathrm{w} / \mathrm{v})$ were mixed with the $1 \%$ agarose gel solution. For casting, the solutions were poured onto 24 -well tissue culture plates $(2 \mathrm{~mL} /$ well $)$ and allowed to solidify at $4^{\circ} \mathrm{C}$. The plates were then transferred into a $-80^{\circ} \mathrm{C}$ freeze-drying oven for $72 \mathrm{~h}$. The resulting scaffolds were incubated with absolute ethanol for $1 \mathrm{~h}$ and immersed in complete media.

\section{In vitro cell cytotoxic assay for the LSF}

BHK and C2C12 cells were grown in 24-well plates at a cell density of $5 \times 10^{3}$ cells/well. Various concentrations $(0-2 \%)$ of filter-sterilized LSF in DMEM media (working concentration $2 \mathrm{mg} / \mathrm{mL}$ ) were added to each well and kept for 3 days. At the $72^{\text {nd }}$ hour of incubation, the cells were washed twice with phosphate buffer saline (PBS), fixed with absolute ethanol, and stained with $0.03 \%$ methylene blue solution to visualize viable cells. To determine cell proliferation, the cells were counted using a hemacytometer.

\section{D culture with $\mathrm{BHK}$ or $\mathrm{C2C12}$ cells}

All cells were cultured in DMEM culture medium and maintained in $5 \% \mathrm{CO}_{2}$ in a $37^{\circ} \mathrm{C}$ incubator. Before seeding into agarose-LSF scaffolds, cells were subcultured to less than $85 \%$ confluency. 3D culture protocols included the following according Sun et al. (2011). Briefly, the cells were dissociated using $0.25 \%$ trypsin-EDTA, resuspended in DMEM to a cell density of $5 \times 10^{3}$ cells $/ 100 \mu \mathrm{l}$ and evenly seeded into each scaffold in a drop-wise manner (100 $\mu \mathrm{l} / \mathrm{scaffold})$. To allow the cells to diffuse and attach, the scaffolds were incubated for $2.5 \mathrm{~h}$ before $1 \mathrm{~mL}$ fresh medium was added. All cell-seeded scaffolds were cultured for 3 weeks to generate tissue engineered cartilage. DMEM was replaced twice a week for the $1^{\text {st }}$ week, and replaced every day for the next 2 weeks.

\section{Imaging of agarose-LSF scaffold and in vitro 3D culture}

Samples were washed with PBS 3 times, fixed in absolute ethanol at $4^{\circ} \mathrm{C}$ for $5 \mathrm{~min}$, and then washed with distilled water. A scanning microscope (MZ16FA, Leica, Wetzlar, Germany) equipped with a Leica camera (DFC490, Leica) was used to examine cell proliferation on the $3 \mathrm{D}$ scaffolds. The cells were then stained with $0.03 \%$ methylene blue solution for $5 \mathrm{~min}$ and washed with PBS 7-8 times to remove excess dye. The cells were visualized by cellular staining with $0.03 \%$ methylene blue dye, and were again viewed using the same scanning optics.

\section{Results and Discussion}

To develop an ultraporous scaffold, aqueous-based agarose solution was mixed with different concentrations of $\mathrm{LSF}$ at various concentrations (0 to $0.05 \%)$. The agarose used in this study melts in water below $65^{\circ} \mathrm{C}$ and forms a gel within a temperature range of $26^{\circ} \mathrm{C}-30^{\circ} \mathrm{C}$. LSF is a light brown fine powder (Fig. 1A). As shown in Fig. 1B, cylindrical scaffolds (diameter $\times$ height: $1.3 \mathrm{~cm} \times 1.0 \mathrm{~cm}$ ) were successfully prepared after freeze-drying. Macroscopically, the porous structure was observed in 3D scaffolds with or without LSF. However, agarose-LSF scaffold showed a more uniform internal spacing and rigid pore size as compared to the agarose scaffold. The internal spacing in the scaffold could be controlled by manipulating the ratio of LSF to agarose. Agarose-LSF scaffold showed a greater susceptibility to shrinkage than the agarose scaffold.

The microporosity of hydrogel scaffolds plays a significant role in the delivery of nutrients and oxygen to the cell, cell attachment, proliferation, and penetration (Park et al., 2010). In a previous study, Stokolsa and Tuszynski (2006) developed porous agarose scaffolds with uniaxial linear channels arranged in a honeycomb pattern by using a freeze-dry fabrication process. These scaffolds integrated well with the host tissue, facilitated cell penetration into individual channels, and allowed axonal growth in a strikingly linear fashion (Stokolsa and Tuszynski., 2006). Park et al. (2010) described a method to fabricate a cellladen agarose gel system containing engineered constructs by using microvascular structures and micropores created by dissolving sucrose crystals without the use of any organic solvents. Their technique led to the development of the porous cell-laden agarose fluidic device (Park et al., 2010). This study thus adopts these methods for the development of porous 3D scaffolds. However, this study minimized the use of chemical solvents to prevent the development of an immune response. The increase in interconnectivity between pores could enhance migration of cells toward internal pores. The device developed in this study is thus characterized by the following features: [1] 2 materials, namely agarose and LSF, that show biocompatibility to the human body, [2] a relatively simple process of mixing agarose and LSF molecules, and [3] uniform interconnectivity of the internal space of the porous scaffolds, regulated by the ratio of LSF to agarose.

To determine the cytotoxicity levels of LSF, cell pro- 


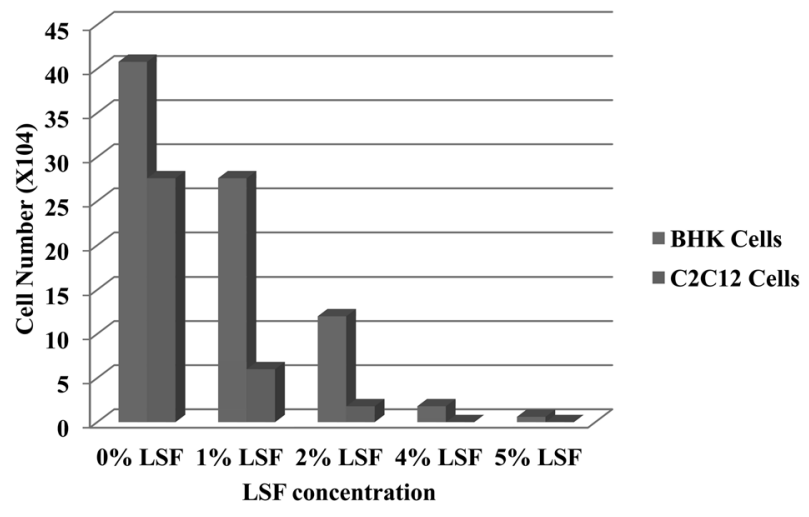

Fig. 2. LSF inhibited the proliferation of $\mathrm{BHK}$ and $\mathrm{C} 2 \mathrm{C} 12$ cells in a dose-dependent manner. The $\mathrm{IC}_{50}$ for $\mathrm{LSF}$ in $\mathrm{BHK}$ cell was over $1 \%(\mathrm{w} / \mathrm{v})$, and thus an LSF concentration $<1 \%$ was chosen as the permitted dose standards for the LSF experiments. The $\mathrm{IC}_{50}$ for $\mathrm{LSF}$ in $\mathrm{C} 2 \mathrm{C} 12$ cells was extremely lower than BHK cells. liferation was measured by direct cell counting using a hematocytometer. As shown in Fig. 2, LSF inhibited proliferation of $\mathrm{BHK}$ and $\mathrm{C} 2 \mathrm{C} 12$ cells in a dose-dependent manner. In our system, the LSF concentration showing $50 \%$ growth inhibition $\left(\mathrm{IC}_{50}\right)$ in $\mathrm{BHK}$ cells was over $1 \%$ $(\mathrm{w} / \mathrm{v})$ and thus, a concentration lower than $1 \%$ was chosen as the LSF dose for the scaffold experiments. The $\mathrm{IC}_{50}$ for LSF in C2C12 cell was extremely low, indicating the need for more experiments with critically low concentrations of LSF. Following LSF treatment for 3 days, cells stained with $0.03 \%$ methylene blue showed a dose-dependent decrease in cell attachment in the 24-well plates (Fig. 3A). The $\mathrm{LSF} \mathrm{IC}_{50}$ for $\mathrm{C} 2 \mathrm{C} 12$ cells was determined to be above $0.2 \%$ (Fig. 3B).

This study does not include any $\mathrm{IC}_{50}$ data for LSF. Recently, it has been reported that LSF increases alkaline phosphatase (ALP) and type I collagen expression in MG63 cells (Kim et al., 2010). Timely degradation of a silk
(A)

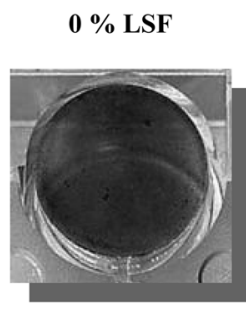

$0.4 \% \mathrm{LSF}$

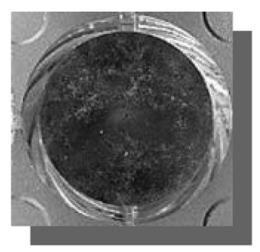

\section{C2C12 Cells}

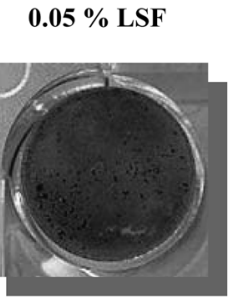

$0.6 \%$ LSF

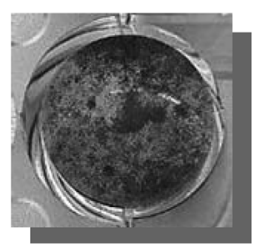

$0.1 \%$ LSF

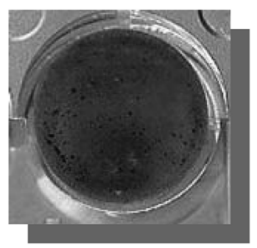

$0.8 \%$ LSF

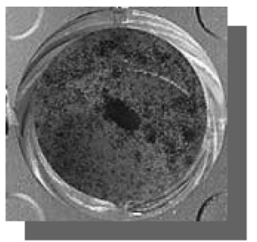

$0.2 \%$ LSF

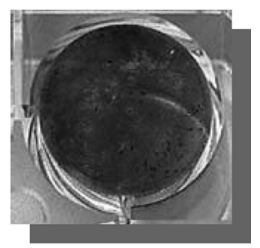

$1.0 \%$ LSF

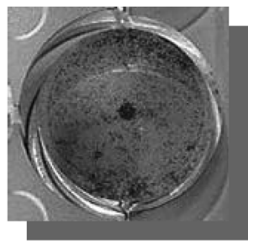

(B)

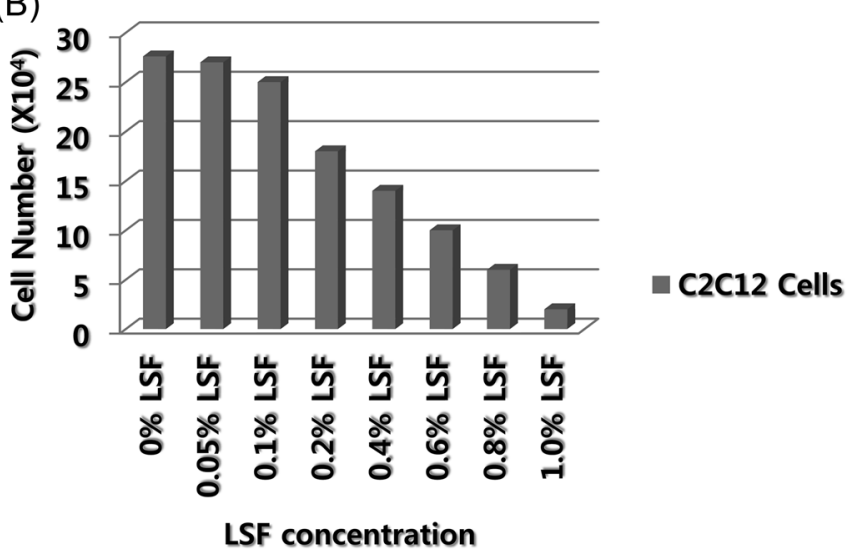

Fig. 3. (A) The cells stained with $0.03 \%$ methylene blue showed a dose-dependent decrease in cell attachment in the presence of LSF. (B) The permitted dose standards for LSF in C2C12 cell is shown as $0.2 \%(\mathrm{w} / \mathrm{v})$. 
(A) culture with $\mathrm{BHK}$ cells

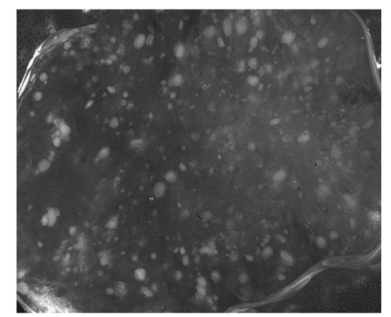

Agarose Scaffold

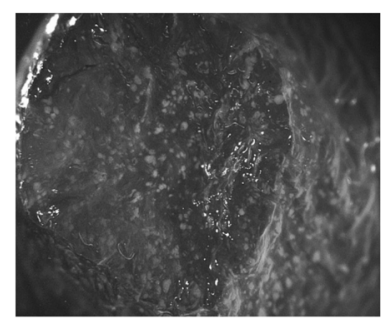

Agarose-LSF Scaffold (0.03\%)

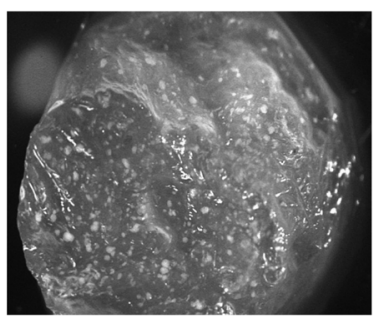

Agarose-LSF Scaffold (0.01\%)

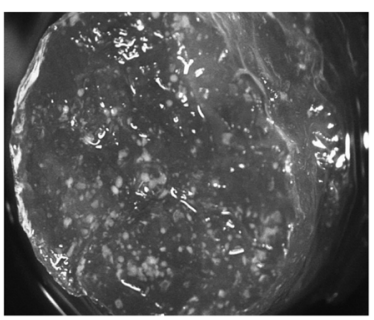

Agarose-LSF Scaffold (0.04\%)

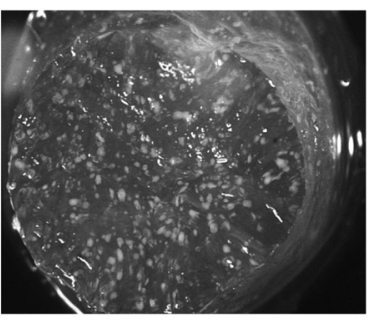

Agarose-LSF Scaffold (0.02\%)

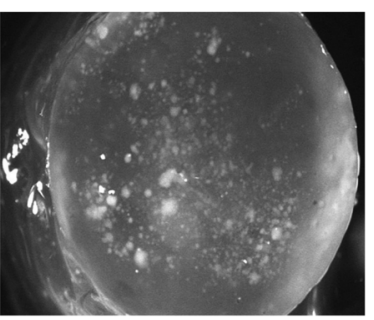

Agarose-LSF Scaffold (0.05\%)

(B) culture with $\mathrm{C} 2 \mathrm{C} 12$ cells

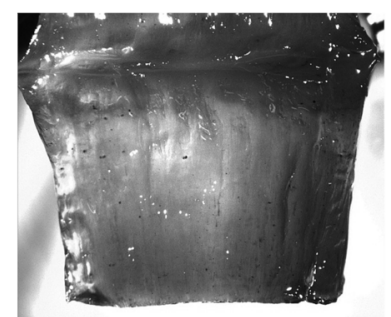

Agarose Scaffold

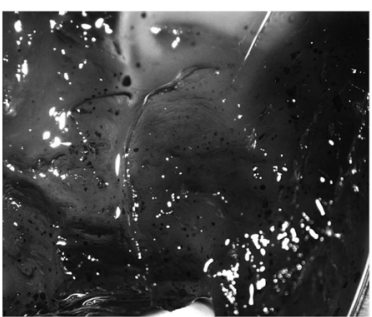

Agarose-LSF Scaffold (0.03\%)

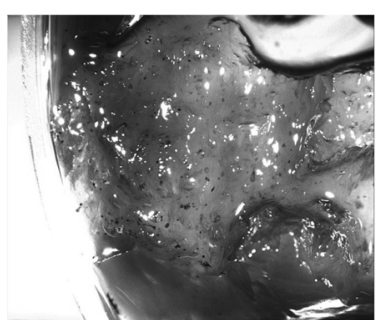

Agarose-LSF Scaffold (0.01\%)

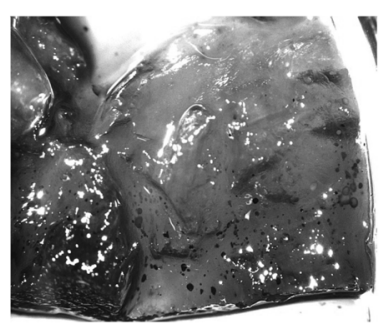

Agarose-LSF Scaffold (0.04\%)

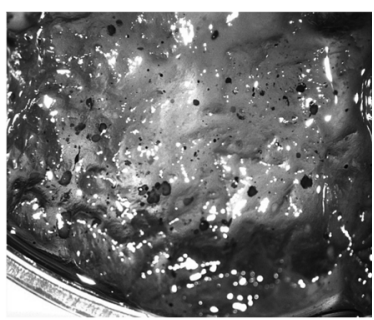

Agarose-LSF Scaffold (0.02\%)

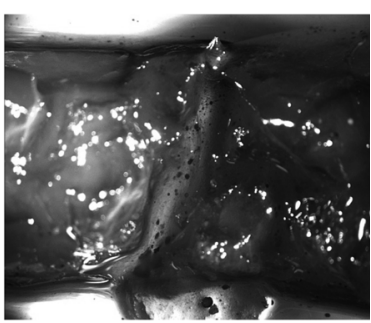

Agarose-LSF Scaffold (0.05\%)

Fig. 4. BHK and $\mathrm{C} 2 \mathrm{C} 12$ cells were seeded onto agarose and agarose-LSF 3D scaffolds. (A) The BHK cells adhered and penetrated into the 3D scaffolds, with the agarose 3D scaffold exhibiting irregular round shape cell colonies. The agarose-LSF scaffold showed comparatively uniformly spaced cells. (B) The scaffold with $\mathrm{C} 2 \mathrm{C} 12$ cells was longitudinally halved using a razor blade and the cell colonies were stained with $0.03 \%$ methylene blue solution. Cell attachment and proliferation was most effective in a 3D scaffold containing $0.02 \% \mathrm{LSF}$.

fibroin scaffold may be useful in the promotion of osteogenesis (Kim et al., 2010). The report also showed that silk fibroin powder was used as a combination template with Choukroun platelet-rich fibrin for the repair of bone defects (Lee et al., 2010). Another group also showed that LSF peptide mixtures promoted 3T3-L1 preadipocyte proliferation (Huang et al., 2010). Therefore, the present study aimed to determine the non-toxic dose for LSF for the tissue engineering research and clinical applications. LSF at varying concentrations [0 to $0.05 \%(\mathrm{w} / \mathrm{v})]$ were mixed with a $1 \%$ agarose gel solution. The maximum allowable amount of LSF that could generate a 3D scaf- 
fold was determined to be $0.05 \%$. As previously mentioned, $\mathrm{IC}_{50}$ concentration of $\mathrm{C} 2 \mathrm{C} 12$ cell was lower $(0.2 \%)$ than BHK cell $(1 \%)$. The LSF concentration in the 3D scaffolds did not exceed the standard concentration.

LSF was conjugated to the agarose hydrogel backbone scaffold to induce cell and biomaterial interactions. BHK and $\mathrm{C} 2 \mathrm{C} 12$ cells were seeded onto agarose and agaroseLSF 3D scaffolds to determine the effect of LSF on cell adhesion and proliferation. Cells adhered and penetrated into the 3D scaffolds (Fig. 4A) and were eventually encapsulated in each scaffold. After 3 weeks, the agarose 3D scaffold exhibited irregular round shape cell colonies, but the agarose-LSF scaffold showed uniformity in the solid culture medium. Agarose-LSF scaffold showed a regular and uniform porous microenvironment in the interior space, possibly regulating cell adhesion and proliferation. When cells attach and proliferate within 3D scaffolds, the interconnected pores of the hydrogel promote cell viability and nutrient and protein transport (Kang et al., 2011). Therefore, the LSF-agarose 3D scaffold containing uniform internal porous structure provided a better microenvironmental condition for cell survival and proliferation. This study has shown the effect of LSF in improving the quality of a 3D scaffold internal microenvironment. Next, we examined the effect of LSF on cell adhesion. The scaffold was longitudinally halved using a razor blade and the cell colonies were stained with $0.03 \%$ methylene blue solution. The 3D scaffolds containing LSF showed more cells that penetrated into the scaffolds as compared to the scaffold without LSF (Fig. 4B). In addition, cell attachment and proliferation was shown to be most effective in a 3D scaffold containing $0.02 \% \mathrm{LSF}$, as compared with others.

To enhance cell attachment and proliferation in a 3D culture system, scaffolds were mixed with several biomaterials derived from natural products, such as collagen (Engelhardt et al., 2011) and chitosan (Xie et al., 2010). Kang et al. (2011) recently reported the chemical conjugation of arginine-glycine-aspartic acid (RGD) peptide into an alginate hydrogel. The RGD conjugation into the alginate hydrogel resulted in the differentiation of human adipose-derived stromal cells (Kang et al., 2011). The authors of this paper were aware of the RGD sequences used to enhance cell/matrix interactions in the design of biomaterials (Kang et al., 2011; Lai et al., 2010), which led to an enhancement of osteogenic differentiation in mesenchymal stem cells (Chun et al., 2009; Kang et al., 2011; Shin et al., 2005). As mentioned above, Kim et al. (2010) reported that LSF increased ALP expression by acting as an osteoblast cell differentiation marker in MG63 cells. This study also supports this observation, wherein LSF led to an enhancement of cell attachment and proliferation. The results of this study may provide useful tools for the promotion of osteogenesis and enhancement of cell/matrix interaction in biomaterial design. To efficiently improve the microenvironment and increase cell attachment and proliferation in scaffolds, hydrogel scaffolds need to be supplemented with LSF, which is a very important step toward 3D scaffold cell culture. This study has some limitations, such as not including the effective LSF concentration that would enhance osteogenic differentiation in bone tissue regeneration. This limitation will be addressed in future studies. 3D culture using an agarose-LSF scaffold is applicable to the induction of bone regeneration, which ultimately facilitates in the process of tissue engineering.

\section{Acknowledgments}

The authors are grateful to Dr. Lee for the kind gift of $\mathrm{C} 2 \mathrm{C} 12$ cell, and Waterborne Virus Bank for the kind gift of BHK cell. This work was supported by a grant (PJ007171022011) from BioGreen21 Program, Rural Development Administration, Republic of Korea.

\section{References}

Aymard P, Martin DR, Plucknett K, Foster TJ, Clark AH, Norton IT (2001) Influence of thermal history on the structural and mechanical properties of agarose gels. Biopolymer 59, 131-144.

Cao Y, Wang B (2009) Biodegradation of Silk Biomaterials. Int. J. Mol. Sc. 10, 1514-1524.

Chun C, Lim HJ, Hong KY, Park KH, Song SC (2009) The use of injectable, thermosensitive poly(organophosphazene)RGD conjugates for the enhancement of mesenchymal stem cell osteogenic differentiation. Biomaterials 31, 6295-6308.

Edelman ER, Nugent MA, Karnovsky MJ (1993) Perivascular and intravenous administration of basic fibroblast growth factor: vascular and solid organ deposition. Proc Natl Acad Sci USA 90, 1513-1517.

Engelhardt E, Micol LA, Houis S, Wurm FM, Hilborn J, Hubbell JA, Frey P (2011) A collagen-poly(lactic acid-co-3caprolactone) hybrid scaffold for bladder tissue regeneration. Biomaterials 32, 3969-3976.

Huang G, Li G, Chen H, He Y, Yao Q, Chen K (2010) Proteomic analysis of 3T3-L1 preadipocytes having a higher cell proliferation rate after treatment with low-molecularweight silk fibroin peptides. Cell Prolif 43, 515-527.

Kang SW, Cha BH, Park H, Park KS, Lee KY, Lee SH (2011) The effect of conjugating RGD into 3D alginate hydrogels on adipogenic differentiation of human adipose-derived stromal cells. Macromol Biosci 11, 673-679.

Kearns V, MacIntosh AC, Crawford A, Hatton PV (2008) Silk- 
based Biomaterials for Tissue Engineering. Topics in Tissue Engineering 4, 1-19.

Kim JY, Choi JY, Jeong JH, Jang ES, Kim AS, Kim SG, Kweon HY, Jo YY, Yeo JH (2010) Low molecular weight silk fibroin increases alkaline phosphatase and type I collagen expression in MG63 cells. BMB Rep 43, 52-56.

Koch MA, Vrij EJ, Engel E, Planell JA, Lacroix D (2010) Perfusion cell seeding on large porous PLA/calcium phosphate composite scaffolds in a perfusion bioreactor system under varying perfusion parameters. J Biomed Mater Res A 95, 1011-1018.

Lai Y, Xie C, Zhang Z, Lu W, Ding J (2010) Design and synthesis of a potent peptide containing both specific and nonspecific cell-adhesion motifs. Biomaterials 31, 4809-4817.

Lee EH, Kim JY, Kweon HY, Jo YY, Min SK, Park YW, Choi JY, Kim SG (2010) A combination graft of low-molecularweight silk fibroin with Choukroun platelet-rich fibrin for rabbit calvarial defect. Oral Surg Oral Med Oral Pathol Oral Radiol Endod 109, e33-e38.

Meinel L, Hofmann S, Karageorgiou V, Kirker-Head C, McCool J, Gronowicz G, Zichner L, langer R, Vunjak-Novakovic G, Kaplan DL (2005) The inflammatory responses to silk films in vitro and in vivo. Biomaterials 26, 147-155.

Park JH, Chung BJ, Lee WG, Kim J, Brigham MD, Shim J, Lee S, Hwang CM, Durmus NG, Demirci U, Khademhosseini A (2010) Microporous cell-laden hydrogels for engineered tissue constructs. Biotech \& Bioeng 106, 138148.

Rahfoth B, Weisser J, Sternkopf F, Aigner T, von der Mark K, Brauer R (1998) Transplantation of allograft chondrocytes embedded in agarose gel into cartilage defects of rabbits. Osteoarthritis Cartilage 6, 50-65.
Santin M, Motta A, Freddi G, Cannas M (1999) In vitro evaluation of the inflammatory potential of the silk fibroin. $\mathrm{J}$ Biomed Mater Res 46, 382-389.

Shin HS, Temenoff JS, Bowden GC, Zygourakis K, FarachCarson MC, Yaszemski MJ, Mikos AG (2005) Osteogenic differentiation of rat bone marrow stromal cells cultured on Arg-Gly-Asp modified hydrogels without dexamethasone and $\beta$-glycerolphosphate. Biomaterials 26, 3645-3654.

Stokolsa S, Tuszynski MH (2006) Freeze-dried agarose scaffolds with uniaxial channels stimulate and guide linear axonal growth following spinal cord injury. Biomaterials 27, 443-451.

Sun L, Wang X, Kaplan DL (2011) A 3D cartilage e Inflammatory cell culture system for the modeling of human Osteoarthritis. Biomaterials 32, 5581-5589.

Tai BC, Wan AC, Ying JY (2010) Modified polyelectrolyte complex fibrous scaffold as a matrix for 3D cell culture. Biomaterials 31, 5927-5935.

Taylor MS, Daniels AU, Andriano KP, Heller J (1994) Six bioabsorbable polymers: in vitro acute toxicity of accumulated degradation products. J Appl Biomater 5, 151-157.

Uludag H, De Vos P, Tresco PA (2000) Technology of mammalian cell encapsulation. Adv Drug Deliv Rev 42, 29-64.

Wang X, Wenk E, Zhang X, Meinel L, Vunjak-Novakovic G, Kaplan DL (2009) Growth Factor Gradients via Microsphere Delivery in Biopolymer Scaffolds for Osteochondral Tissue Engineering. J Control Release 134, 81-90.

Xie D, Huang H, Blackwood K, MacNeil S (2010) A novel route for the production of chitosan/poly (lactide-co-glycolide) graft copolymers for electrospinning. Biomed. Mater $5,1-9$. 